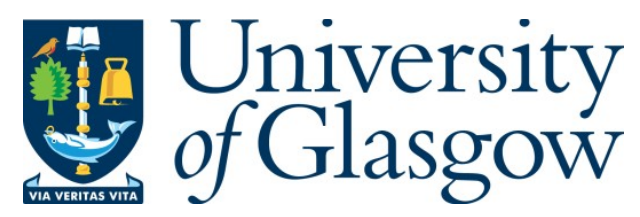

Simion, M. (2020) Social epistemology of education. In: Peters, M.

A. (ed.) Encyclopedia of Educational Philosophy and Theory. Springer. ISBN 9789812875327

(doi: 10.1007/978-981-287-532-7 696-1)

This is the Author Accepted Manuscript.

There may be differences between this version and the published version. You are advised to consult the publisher's version if you wish to cite from it.

$\underline{\text { https://eprints.gla.ac.uk/222810/ }}$

Deposited on: 9 September 2020

Enlighten - Research publications by members of the University of Glasgow http://eprints.gla.ac.uk 


\title{
The Social Epistemology of Education
}

\author{
Mona Simion \\ University of Glasgow, COGITO Epistemology Group \\ Glasgow, UK \\ mona.simion@glasgow.ac.uk
}

\section{Introduction}

The theory and practice of education raises a number of interesting epistemological questions; after all, it is prima facie plausible that education is concerned with generating some variety of another of epistemic goods (knowledge, understanding, rational belief, critical thinking, cognitive skills etc.) in the target population. If that is so, two questions that readily arise are: (Q1) What is the fundamenital epistemic aim of education?, and (Q2) How should we proceed in our practice of education in order to reliably achieve the aim in question?. Since both of these questions are normative rather than descriptive i.e., they concern issues pertaining to epistemic value and epistemic normativity epistemological expertise is needed to make progress towards answering them.

That being said, while philosophers have long been concerned with answering these questions, it is arguable that it is only in the last three decades that epistemologists have thoroughly developed the right theoretical tools for approaching the issue. That is because, until very recently, epistemology was highly individualistic in focus: it conceived of the epistemic subject in isolation from her social milieu and, as a result, it laid most of the burden of epistemic work on the shoulders of the individual (Goldman 1999). However, individualist epistemology is, fairly clearly, not in the best position to answer questions pertaining to the epistemology of education. After all, education is, structurally, a social epistemic setting and the paradigmatic scene for epistemic dependence on others. With the rise in interest in social epistemological issues in cotemporary philosophy, however, the epistemology of education has benefitted from both increased interest from practitioners and impressive progress. 
This article will survey some of the most important strands of research in contemporary social epistemology of education. Section \#2 is concerned with contemporary debates on the fundamental epistemic aim of education (Q1). Sections \#3 and \#4 will address Q2, by looking, in turn, at the epistemic responsibilities of speakers and hearers involved in testimonial exchanges in educational settings.

\section{The Fundamental Epistemic Aim of Education}

The debate concerning the epistemic aim of education divides theorists in two broad camps: first, there are people who think that the practice of education aims at generating one variety or another or epistemic status in students (henceforth, the Status View) knowledge, true belief, justified belief, understanding etc. In contrast, several philosophers of education claim that education essentially aims at generating epistemic skills, such as epistemic virtues, critical thinking, dispositions to reason well etc. (henceforth, the Skills View).

\subsection{The Epistemic Status View}

Alvin Goldman, notably, is a defender of a veritistic Status View: according to Goldman (1999), all of our epistemic endeavors aim at truth, and the practice of education, in virtue of being essentially an epistemic practice, makes no exception. To be sure, Goldman does acknowledge that developing epistemic skills such as dispositions to reason well and critical thinking abilities are important values to be observed by and developed through our practice of education. However, on his veritistic account, epistemic skills are merely instrumental to the acquisition of true beliefs.

Now, worries about a picture on which truth is our chief epistemic aim have been ubiquitous in epistemology and beyond. First, the necessity claim involved in veritism has been questioned on historical grounds. Frederick Schmitt (2005), for instance, maintains that the primary aim of education is justified belief (where the latter takes a traditional, non-factive shape). The thought goes as follows: many of our scientific theories proved, historically, to be false: take Aristotelian physics for instance. 
Do we want to say that, given that his physics was mostly mistaken, Aristotle's education must have been somehow deficient? Schmitt's reported intuition is that this would be the wrong result.

The most notable and widely spread worry about veritism, however, regards the sufficiency claim: after all, it seems implausible that, for instance, mere lucky true belief acquired via a coin toss is a particularly valuable epistemic status. Similarly, we want our educators to teach our children things that they don't merely believe based on a lucky guess. Nor do we want our children to acquire true belief via brainwashing or indoctrination.

Unsurprisingly, the main competition for veritistic pictures are knowledge-aim accounts. In virtue of knowledge being incompatible with luck and improper belief formation, it is easy to see that these views will avoid the problems of veritism. Jonathan Adler (2003) defends a knowledge-based Status View of the fundamental aim of education. He argues that 'the knowledge-aim offers educational guidance, justifies central educational practices, and exposes complexities in the educational policies it supports' $(2003,285)$.

Several people in the Status View camp, however, are dissatisfied with knowledge-based accounts for being yet too weak. According to Duncan Pritchard (2013), for instance, understanding is the fundamental epistemic value and, thus, the fundamental goal of education. Importantly, most epistemologists agree that understanding requires something over and above truth or knowledge, something like grasping the relations between separate knowledge items (e.g. Kelp 2015).

\subsection{The Epistemic Skill View}

We have seen that a number of defenders of the Status View agree that the acquisition of cognitive skills is an important value to be generated by education. However, in their view, this is a mere instrumental value, serving the ultimate, fundamental aim of truth, or knowledge.

Champions of skill-based accounts disagree with the latter claim; they agree that true belief and knowledge are important values in education, but, in contrast to defenders of the Status Views, these philosophers take generating some variety of another of cognitive skill to be an independent aim of education. 
Most notably, Harvey Siegel (2005) argues that, on top of generating true beliefs, fostering critical thinking skills in students is a final goal of the practice of education in itself, independently of its conduciveness to the acquisition of true beliefs. On his view, education should also aim to develop "skills, abilities and dispositions constitutive of critical thinking, and the rational belief generated and sustained by it" (2005: 347).

Another line of resistance against Status Views comes from virtue responsibilism in epistemology. Jason Baehr (2011) notably defends the fostering of the intellectual virtues such as open mindedness, intellectual humility and curiosity as the fundamental epistemic aim of education.

Why should we abandon the Status View for a Skill View? Most arguments in the latter camp aim to support this sort of pluralism about the fundamental goal of education from the eminently plausible thought that brainwashing students into believing truly can't possibly be an instance of successful education, like veritism would seem to predict. Note, though, that this argument, even if successful against veritism, will not work against knowledge or understanding-based views, since neither is acquirable via brainwashing. More needs to be said.

The plausible thought behind Skill Based views seems to be that, very roughly, we should teach students how to fish themselves, rather than catch the fish for them. This seems right. We want people to be skilled enough to inquire on their own even after they complete their education. Does this, however, show that critical thinking skills, open mindedness, curiosity and so on are epistemically good things independently of their conduciveness to truth or knowledge (within or outwith school)? Not necessarily. To see this, consider the following case: Mary's father, John, is thinking about what school to send his daughter to: at School A, the practice aims at generating knowledge in students. In contrast, School B has a pluralist approach, also focused on fostering open mindedness. Now, here's the twist: Mary is an extremely gifted cognitive agent; in fact, she is in the top $3 \%$ of her generation. In virtue of this, were she to go through life being quite dogmatic in her beliefs, Mary would end up with more knowledge, in virtue of lack of psychological defeat from the testimony of others. In contrast, were she to be openminded, Mary will often loose confidence in her knowledgeable beliefs and acquire false beliefs base don the testimony of others. Should (epistemically!) John choose School B over School A? Intuitively, the answer is 'no.' If this is so, it suggests that, while open mindedness and other epistemic virtues are contingently epistemically valuable, in virtue 
of being conducive to good epistemic statuses, they are not goods to be valued for their own sake (for an excellent overview see (Carter and Kotzee 2015).

\section{Norms of Assertion in Classroom Settings}

We have seen the issue of the fundamental epistemic aim of education is rather controversial. Here is, though, one uncontroversial thought: whatever the aim in question might be, it will largely be achieved via the speech act of assertion: by teachers telling their students that this or that is the case.

Here is something that sounds extremely plausible: we want our children's teachers to know what they're talking about. To see this, note that, were we to find out otherwise, we would likely not be particularly happy. This suggests the following norm of assertion in educational settings:

One must: assert that $\mathrm{p}$ only if one knows that $\mathrm{p}$ (henceforth the knowledge norm of assertion, or KNA).

KNA is widely endorsed in epistemology at large, and supported by a vast amount of theoretical and empirical considerations. It also seems to fit well with several views on the fundamental aim of education; after all, uncontroversially, the most reliable way to generate knowledge in hearers is by asserting from knowledge. Note, also, that the same holds for a true-belief-goal view: in virtue of the kind of creatures we are, our most reliable way of getting at the truth is by knowing it - lucky true belief is not that ubiquitous.

In spite of all these advantages, KNA faces a forceful objection coming precisely from the epistemology of education. Consider the following case by Jennifer Lackey:

CREATIONIST TEACHER: Stella is a devoutly Christian fourth-grade teacher; as such, she strongly believes in the truth of creationism and, accordingly, in the falsity of evolutionary theory. Despite this, Stella fully recognizes that there is an overwhelming amount of scientific evidence against both of these beliefs. Stella regards her duty as a teacher to include presenting material that is best supported by the available evidence. As a result, while presenting her biology lesson today, Stella asserts to her students, 
"Modern day Homo sapiens evolved from Homo erectus," though she herself neither believes nor knows this proposition (adapted form Lackey $(2007,548)$ ).

Lackey argues that Stella "offers an assertion in the absence of knowledge and is not properly subject to criticism" $(2007,549)$. That seems right. Now, several people (e.g. ) have argued that Stella's intuitive blamelessness can easily be explained by normative overriding: in this case, it is argued, professional norms override the epistemic norm of assertion, rendering the asserter blameless for violating the epistemic norm.

Note, though, that while this answer might work well enough for epistemology at large, it will not do for settling our question here. That is because the relevant professional norms will always be active in educational settings.

The alternative, most prominent account of the norm of assertion proposed in the literature is a justification norm (JNA), defended, most notably, by Jennifer Lackey:

One must: assert that only if $\mathrm{p}$ is reasonable for one to believe.

It is easy to see that JNA deals well with the Creationist Teacher's case: after all, Stella is asserting from what she takes to be the theory best supported by evidence. Note also that Stella's case is one in which, in spite of lack of knowledge on the speaker's side, the assertion does have the potential to generate knowledge in students: if they believe what Stella tells them, they will come to know that modern day Homo sapiens evolved from Homo erectus. This suggests that, while asserting from knowledge might be the most reliable way to go about generating knowledge in hearers, it is not necessary to this aim.

There is, however, also a problem for JNA as the norm of assertion in educational settings: the defender of JNA will get in trouble with most of the Status theorists about the goal of education. To see this, note that JNA is not factive, while most Status-based proposals are. It is not easy to see why we would have a norm of assertion for educational settings that fails to observe the fundamental aim of the practice. In virtue of this, JNA-champions will have a hard time aligning their view to some of the most widely endorsed views of the aim of education on the market.

\section{Trust and Testimony}


The previous section was concerned with norms governing teachers' speech acts in educational settings. This section moves on to norms governing hearer's beliefs based on teacher's testimony.

Here is one attractive thought: We believe what other people tell us, and that's all right. Elaborated detective work to verify the credentials of the testifier is not necessary. This view comes by the name Anti-Reductionism (ART) about testimonial justification (e.g. Graham...). It is anti-reductionist in that it holds that testimonial justification does not depend on other epistemic sources, such as perception or induction.

Now, say ART is true; one interesting philosophical question that arises is how come testimonial entitlement comes so cheap. After all, people are free to lie. Furthermore, they are rational to attend to their own interest, rather than someone else's. Let us dub this problem the Source Problem for testimonial justification (SP): it concerns the source of our justification to believe what we are being told by other people, on mere say-so.

Several philosophers think the Source Problem motivates a departure from AntiReductionism in the direction of a Reductionist view (RT) of testimonial justification (e.g. Fricker...): according to this account, we are not justified to believe people on mere sayso: we need positive, independent reasons to justify our belief. The view is reductionist in that it holds that testimonial justification depends on other epistemic sources.

It is easy to see how this debate in the general epistemology of testimony translates swiftly to the social epistemology of education: on the one hand, the educational epistemic setting seems like the paradigmatic setting to motivate ART. After all, students are extremely epistemically dependent on their teachers. On the other hand, there is a clear sense in which uncritical acceptance of teacher's testimony is not something we want from our students.

The question that arises, then, is a variety of SP for educational settings: in virtue of what are students epistemically justified to believe what they are being told by their teachers?

It would seem, on the face of it, that Reductionism has an easy answer to this question: the educational setting is such that students do have inductive reasons to trust their teachers; after all, teacher testimony is institutionalised testimony. Since we all have a very broad inductive basis for trusting this institution institution - it has delivered quality information for centuries - students are justified to believe what they are being told. Note, however, that this response, while it might work for sophisticated student 
cognizers, it will not do the trick for small children. Two reasons for this: first, it is empirically implausible that children have the requisite reflective capacities to reason in this way at an early age. Second, even if they were to be psychologically capable to draw the relevant inference, it is highly unlikely that they are in possession of the relevant inductive evidence to begin with. In this, Reductionism over-intellectualizes testimonial justification in classroom settings.

Several anti-reductionists give a social-norms-based solution to the SP problem: according to (Graham 2006) and (Simion, Forthcoming), for instance, the source of testimonial epistemic entitlement lies in the social norms governing our testimonial exchanges (such as truth-telling, or KNA). Accoridng to Graham, since a truth-telling norm or is in place, testifiers have prima facie reason to tell the truth, absent overriding considerations. If testifiers have prima facie reason to tell the truth, hearers have prima facie reason to trust their testifiers. It is easy to see how this view will neatly answer SP for educational settings: after all, our practice of education is, if anything, more strictly regulated by some variety of truth telling norms than our everyday testimonial exchanges. Furthermore, arguably, it rarely happens that teachers will have strong incentive to lie to their students.

AR nicely explains the intuition that it is permissible for children to believe what they are being told by their teacher without searching for further evidence. The worry for AR, however, is that it may licence gullibility on student's side, on the one hand, and indoctrination in the classroom on the other.

One way to appease this worry on AR's behalf is to supplement their account with anti-defeat conditions. Peter Graham takes this route: his version of AR stipulates an extra defeat filtering condition on justification. According to Graham, when we believe on mere say-so, we employ an active anti-defeat filtering mechanism that monitors the social environment for signs of deception. It is easy to see how this account will have an easier time appeasing the gullibility worry: were the students to detect defeat, they would not believe base don teacher's testimony. One question that arises, however, is how plausible it is that small children are good at filtering for defeat.

\section{Concluding Remarks}


It is impossible to do justice to the whole field of the social epistemology of education in one encyclopaedia entry. And that is great news: it shows with the rise of interest and research in social epistemology, we have developed excellent tools for approaching social-epistemic issues arising in the theory and practice of education, and we can make significant progress in the field.

\section{References}

Adler, J. (2003). Knowledge, Truth and Learning, in Curren A Companion to the Philosophy of Education, Oxford: Blackwell: 285-304.

Baehr, J. (ed.), 2016, Intellectual Virtues and Education: Essays in Applied Virtue Epistemology, New York: Routledge.

Carter, J.A. and Kotzee, B. (2015) Epistemology of Education, Oxford Bibliographies Online, last modified: 26 October 2015.

Fricker, E., 1987, “The Epistemology of Testimony”, Proceedings of the Aristotelian Society Supplementary, 61: 57-83.

Goldman, Alvin I. (1999) Knowledge in a Social World, Oxford: Oxford University Press.

Graham P. (2006). Testimonial Justification: Inferential or Non-inferential. Philosophical Quarterly, 56: 84-95.

Kelp, C. (2015). Understanding Phenomena.In Synthese 192: 3799-3816.

Lackey, J. (2007). Norms of Assertion. Noûs 41: 594-626.

Pritchard, D. (2013) Epistemic Virtue and the Epistemology of Education, Journal of Philosophy of Education, 47(2): 236-247.

Schmitt, F. (2005). What Are the Aims of Education?. Episteme 1 (3):223-234.

Siegel, H. (2005) Truth, Thinking, Testimony and Trust: Alvin Goldman on Epistemology and Education, Philosophy and Phenomenological Research, 71(2): 345-366.

Simion (Forthcoming). Testimonial Contractarianism. Nous. 